A relação entre concomitância e convergência na análise da integração do SN ao verbo The relation between concomitance and convergence on the analysis of the NP integration in the verb

Bruna Karla Pereira (UFMG) Apoio (FAPEMIG)

Resumo: Discutiremos três tipos de integração de SN à instância verbal: a integração do $S N$ constitutivo do adjunto, a integração do $S N$ constitutivo do objeto e a integração do $S N$ em verbos que se apresentam como condensativos. Com esta discussão, pretendemos explicar como se dá o funcionamento de verbos como "chover", no que se refere à integração do SN "chuva" e à convergência dos lugares sintáticos de sujeito e objeto, neste SN integrado.

Palavras-chave: integração do SN, desmembramento do SN, concomitância e convergência.

Abstract: This paper intends to discuss three types of NP integration into the verb: the integration of the NP that makes part of the adverbial adjunct, the integration of the NP that makes part of the direct object and the integration of the NP with verbs which act as condensative verbs. With this discussion, we intend to explain how verbs like "chover" work in relation to the integration of the NP "chuva" and also in relation to the convergence of subject and object at this integrated NP.

Key words: NP integration, NP detachment, concomitance and convergence.

\title{
0 Introdução
}

Em Dias \& Pereira (2007), apresentamos fenômenos cuja análise mostra uma simultaneidade de categorias morfológicas e sintáticas na cadeia lingüística. Dentre estes fenômenos, alguns ocupam um grau mais alto na escala de concomitância, e outros, graus mais baixos. Sendo assim, observamos que o que determina a intensidade da concomitância é a possibilidade ou não de desmembramento destas categorias.

Por isso, percebemos que, na Morfologia, o morfema cumulativo ocupa o grau mais alto nesta escala, tendo em vista que não é possível desmembrar as categorias de tempo e modo do morfema "ra", em "bebêramos", por exemplo. Assim, sempre que "ra" ocorrer, ele indicará pretérito mais que perfeito do indicativo. De modo diferente, em um composto por aglutinação, como "planalto", é possível desmembrar e identificar, em sua linearidade, 
os dois vocábulos que o constituem: "plano" e "alto". Por isso, a composição por aglutinação ocupa uma posição baixa na escala morfológica de concomitância.

Por sua vez, na Sintaxe, observamos que a convergência dos lugares sintáticos de sujeito e objeto direto ocupa a posição mais alta na escala, tendo em vista que não é possível desmembrar "Houve desastres", em uma sentença na qual "desastres" ocupe o lugar de sujeito, e, em outra, na qual "desastres" ocupe o lugar de objeto.

Diferentemente, vimos que, no princípio de concomitância, conforme proposto por Seiler (1975), a simultaneidade de predicação principal (PRED) e de predicação acessória (PRED') ocupa um baixo grau na escala sintática. Por exemplo, em "Seymour cortou o salame com uma faca" ${ }^{1}$, há duas atribuições ao sujeito: a predicação principal "cortou 0 salame" e a predicação acessória "com uma faca". Assim sendo, Seymour é tanto o cortador do salame quanto o portador da faca. Por isso, há duas predicações concomitantes na sentença, que são duas injunções operando concomitantemente sobre o sujeito. Entretanto, esta concomitância ocupa um grau baixo na escala, porque as duas categorias (PRED e PRED') são identificadas separadamente na linearidade da sentença.

Ainda, quanto ao princípio de concomitância, discutimos a distinção de Seiler entre ocorrências de instrumental marcadas e não-marcadas. Para ele, ocorrências nãomarcadas são aquelas em que o verbo pode ser extraído de um nome deverbal presente em "com SN". É o caso da sentença (1b), que pode ser extraída de (1a), exemplos de Seiler (1975, p. 183):

(1a) Avec un sourire tu obtiens plus. (Com um sorriso, você cativa mais.)

(1b) Si tu souris tu obtiens plus. (Se sorrir, você cativa mais.)

Por sua vez, ocorrências marcadas são aquelas em que o SN não é deverbal e, portanto, não é possível extrair dele um verbo. Neste caso, é necessário escolher verbos de utilização, tais como "usar" e "utilizar". Assim, uma paráfrase de (2a) será (2b), exemplos também de Seiler (1975, p. 188):

(2a) Max coupe le poisson avec un couteau. (Max corta o peixe com uma faca.)

(2b) Max utilize un couteau por couper le poisson. (Max usa uma faca para cortar o peixe.)

No entanto, observamos que esta diferença entre instrumental marcado e nãomarcado não se aplica generalizadamente ao português, tendo em vista uma sentença como:

(1c) Max faqueou o peixe.

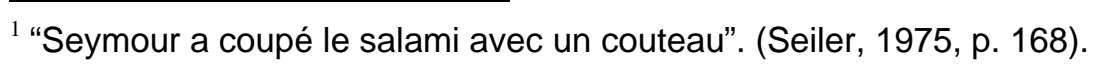


Nesta paráfrase, não foram necessários verbos de utilização, porque, do nome "faca", pode ser extraído o verbo "faquear". Neste caso, propusemos uma integração, no verbo "faquear", do SN "a faca", constitutivo do adjunto "com a faca".

Neste artigo, desdobraremos esta análise a, pelo menos, três tipos de integração de SN à instância verbal: a integração do SN constitutivo do adjunto, a integração do SN constitutivo do objeto e a integração do SN em verbos que se apresentam como condensativos. Com esta análise, pretendemos explicar como se dá o funcionamento de verbos como "chover", no que se refere à integração do SN - neste caso, "chuva" - e à convergência dos lugares sintáticos de sujeito e objeto, neste SN integrado. Além disso, abordaremos um fenômeno nos estudos lingüísticos que tem recebido a designação "formas convergentes", mas se trata de algo distinto daquilo que estamos designando convergência.

\section{A integração do SN constitutivo do adjunto no núcleo do predicado}

Observemos as seguintes sentenças:

(3) Ronaldinho cabeceou a bola.

(4) João martelou o prego.

(5) Pedro faqueou o peixe.

Nelas, observamos que os SNs dos adjuntos "com a cabeça", "com o martelo" e "com a faca" estão integrados respectivamente nos núcleos "cabeceou", "martelou" e "faqueou". Estas sentenças, portanto, podem ser paráfrases das que se seguem:

(3a) Ronaldinho tocou a bola com a cabeça.

(4a) João bateu o prego com o martelo.

(5a) Pedro cortou o peixe com a faca.

Nestas paráfrases, o SN constitutivo do adjunto é desmembrado do verbo. Podemos dizer que este desmembramento é total. Primeiro, porque o SN cognato deixou de estar aglutinado no núcleo verbal e passou a fazer parte do adjunto adverbial. Além disso, os verbos "cabecear", "martelar" e "faquear" foram substituídos por "tocar", "bater" e "cortar", perdendo, portanto, a aglutinação.

Entretanto, há casos em que este desmembramento é parcial apenas, tendo em vista que tanto o verbo integrador quanto o SN cognato estarão presentes na sentença. $\mathrm{O}$ primeiro sendo núcleo do predicado, e o segundo compondo o adjunto adverbial. Vejamos:

(3b) Ronaldinho cabeceou a bola com a cabeça inclinada.

(4b) João martelou o prego com um martelo enferrujado. 
(5b) Pedro faqueou o peixe com uma faca afiada.

Nestes casos, o verbo não é alterado, como ocorre de (3a) a (5a). Por isso, a lexicalização do cognato no adjunto não desfaz a concomitância que há, no verbo "martelar", entre o feixe semântico ${ }^{2}$ envolvendo "com um martelo" e o feixe semântico envolvendo "bater". Entretanto, devido à necessidade de um detalhamento ou de uma especificação maior do SN, é necessário que ele se desmembre da instância verbal para se constituir como item léxico.

Assim, não há um desmembramento total, tendo em vista que o feixe semântico relativo a "com o martelo" ainda está integrado ao núcleo do predicado, mesmo que o SN cognato tenha sido lexicalizado na sentença. Do mesmo modo, os feixes semânticos relativos a "com a cabeça" e "com a faca" ainda se constituem como feixes semânticos dos verbos "cabecear" e "faquear", em (3b) e em (5b). Podemos afirmar, portanto, que, embora tenha ocorrido um desmembramento sintático, na linearidade da sentença, não houve um desmembramento semântico.

Por fim, ainda temos as seguintes possibilidades:

(3c) Ronaldinho cabeceou a parede com o capacete, só pra fazer gracinha.

(4c) João ficou martelando a mesa com a caneta, só para irritar a professora.

(5c) Pedrinho tentava faquear o peixe com um pedaço de pau, imitando a faca de seu pai. Nestes casos, proporíamos um desmembramento também, porém mais efetivo que aquele apresentado de (3b) a (5b) e mais próximo daquele apresentado de (3a) a (5a). Este desmembramento é mais efetivo que aquele de (3b) a (5b), tendo em vista que o adjunto adverbial não é constituído por um nome cognato. Assim sendo, os verbos "cabecear", "martelar" e "faquear" são destituídos, respectivamente, dos traços "com a cabeça", "com o martelo" e "com a faca", porque o feixe semântico instrumental destes verbos foi modificado nas sentenças por "com o capacete", "com a caneta" e "com um pedaço de pau".

Entretanto, não se trata também de um desmembramento total, tendo em vista que os verbos não foram alterados, como ocorreu de (3a) a (5a). Portanto, embora eles tenham perdido os traços semânticos relativos a "com a cabeça", "com o martelo" e "com a faca", estes verbos ainda estão presentes na sentença e guardam os feixes semânticos referentes, respectivamente, a "mover a cabeça", "tocar com força e repetidamente" e "golpear". Sendo assim, enquanto a desmembramento do SN, em um adjunto, leva a um desmembramento total na dimensão orgânica da sentença, a substituição do SN cognato

\footnotetext{
${ }^{2}$ Estamos entendendo "feixe semântico" como um conjunto mínimo de traços que determinam a significação em uma direção x ou y.
} 
leva a um desmembramento somente parcial semanticamente. É parcial porque, embora o SN cognato tenha sido alterado, o verbo permanece na sentença, com feixes semânticos que, antes, eram concomitantes aos sentidos instrumentais, regularmente atribuídos a estes verbos. Nesse sentido, a concomitância não se desfaz plenamente, mas também não possui um grau alto.

Portanto, poderíamos projetar uma escala de concomitância para estas ocorrências, como se segue:

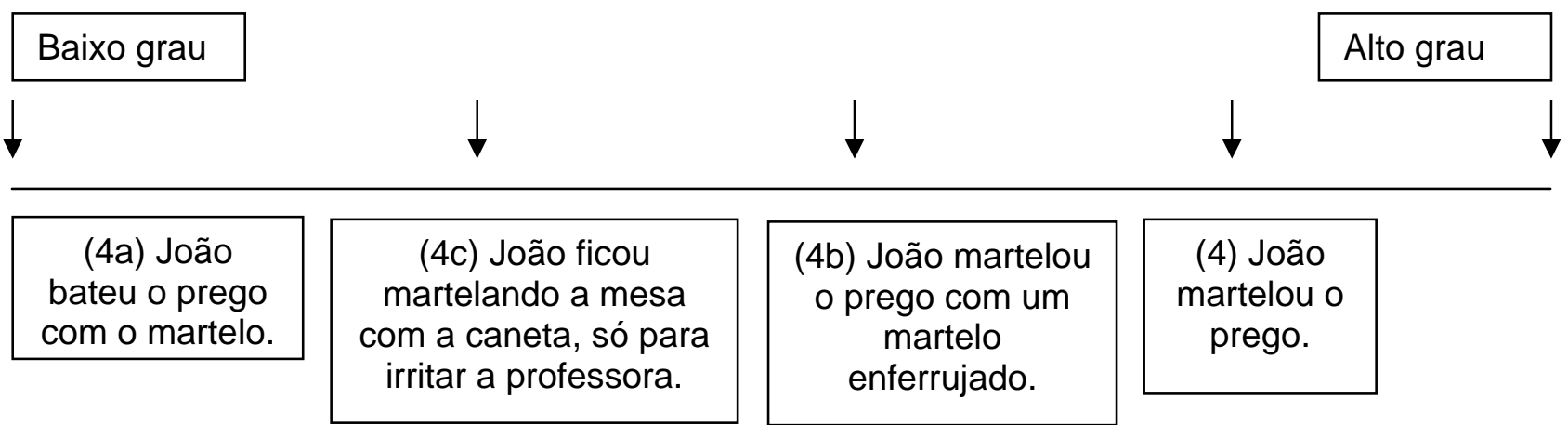

Nesta escala, percebemos que, embora cada uma destas ocorrências apresente graus mais baixos ou graus mais altos de concomitância, nenhuma delas atinge o máximo grau. Isto se deve ao fato de que a concomitância, nestes casos, pode ser desfeita pelos processos de desmembramento anteriormente explicitados.

\section{A integração do SN constitutivo do objeto no núcleo do predicado}

Vejamos as seguintes sentenças:

(6) André cuspiu (PERINI, 1992, p. 79).

(7) João urinou.

De acordo com Perini (1992, p. 79),

"Neste caso, a omissão do objeto parece ligar-se à alta previsibilidade de um objeto específico, algo como "cuspe". Digamos que o verbo cuspir (...) carrega consigo uma expectativa muito alta de que "a coisa cuspida" seja cuspe e não, digamos, sangue ou guaraná. Tanto é assim que a explicitação do objeto (...) só ocorre quando há reversão da expectativa (...) Outra situação seria o caso de se pretender qualificar o objeto esperado".

Assim sendo, Perini (1992) mostra duas situações nas quais pode haver objeto (compreendido por ele como item lexical) com o verbo "cuspir". Uma delas é quando há uma reversão na expectativa, como em:

(6a) André cuspiu sangue (PERINI, 1992, p. 79).

Outra situação é quando se faz necessário caracterizar o SN, como em:

(6b) André cuspiu um cuspe grosso (PERINI, 1992, p. 80). 
$\mathrm{Na}$ nossa perspectiva, estamos compreendendo sentenças, como estas apresentadas por Perini (1992), como casos em que o SN, constitutivo do objeto, está integrado à instância verbal. Assim, propomos que os SNs "cuspe" e "urina" estariam aglutinados aos verbos "cuspir" e "urinar", em (6) e em (7), respectivamente. Por sua vez, em (6a), há um desmembramento entre "cuspe" e "cuspir", apenas na organicidade da sentença, porque o objeto lexicalizado é "sangue" e não, "cuspe". No entanto, mesmo que o verbo "cuspir" tenha perdido o feixe semântico relativo a "cuspe", ele ainda mantém o feixe semântico relativo ao ato de "ejetar" ou "expelir" algo, antes concomitante ao traço "cuspe". Sendo assim, podemos afirmar que, embora o desmembramento seja forte, tendo em vista a lexicalização do objeto e a destituição do traço semântico "cuspe", ainda permanecem outros feixes semânticos. Por isso, podemos dizer que este desmembramento é intenso, mas não é total, porque permanece um resquício de traços, que eram concomitantes a "cuspe", em (6), por exemplo.

Do mesmo modo, podemos analisar:

(7a) João urinou um cálculo renal.

Nesta sentença, embora o verbo "urinar" tenha se destituído do feixe semântico relativo a "urina" e tenha se lexicalizado na posição de objeto por um SN não-cognato, este verbo ainda permaneceu na sentença. Ao permanecer na sentença, o verbo "urinar" resguarda o feixe semântico relativo ao ato de "verter" ou "expelir", antes concomitante a "urina", como em (7). Por isso, temos um desmembramento na linearidade da sentença, mas um desmembramento parcial na constituição semântica do verbo, que guarda a memória de uma antiga concomitância ali existente. Portanto, não se trata de um desmembramento total.

Entretanto, em observação às sentenças:

(6b) André cuspiu um cuspe grosso

(7b) João urinou uma urina muito concentrada,

não podemos afirmar que o SN cognato desmembrou-se totalmente, tendo em vista que o feixe semântico relativo a "urina" ou a "cuspe" permanecem integrados ao verbo. Nesse sentido, propomos que este desmembramento se dá, apenas, na organicidade da sentença, tendo em vista a necessidade de especificar o SN cognato, sem causar uma destituição de feixes semânticos no verbo.

Assim, embora o SN tenha se desaglutinado do verbo, sintaticamente, a concomitância ainda permanece nos traços semânticos que o verbo comporta. Por isso, trata-se de um desmembramento parcial, porém menos intenso que aquele apresentado em (6a) e em (7a). Nestas sentenças, houve destituição de traços semânticos dos verbos, 
diferentemente, em (6b) e em (7b), não houve destituição de traços semânticos, apenas desmembramento no âmbito sintático, dada uma necessidade de adjetivação do SN cognato.

Para estas ocorrências, também poderíamos propor uma escala de concomitância como a que se segue:

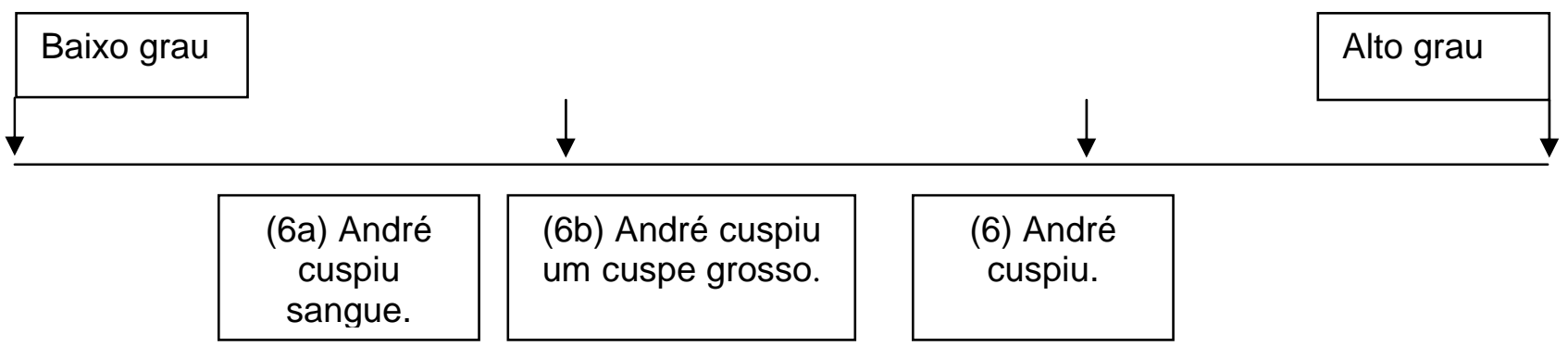

Nesta escala, nenhuma destas ocorrências apresenta o máximo grau de concomitância, tendo em vista que a integração, em (6), pode ser desfeita, conforme foi explicado na análise de (6a) e de (6b). Além disso, nenhuma destas sentenças ocupa o grau mínimo porque, mesmo havendo desmembramento, ele foi parcial.

\section{A integração do SN em verbos que se apresentam como condensativos}

A análise dos verbos representativos de fenômenos meteorológicos, neste momento, é pertinente, porque eles apresentam a possibilidade de um diálogo tanto no que se refere ao escopo amplo da concomitância quanto ao escopo específico da convergência. Por isso, consideraremos, em primeira instância, uma análise da integração do SN, na instância verbal. Posteriormente, ressaltaremos a possibilidade de uma convergência dos lugares sintáticos de sujeito e objeto direto, neste SN, sem que ele seja lexicalizado na sentença ou recuperável em outra oração. Assim, constataremos que a convergência dos lugares sintáticos de sujeito e objeto não ocorre apenas quando o SN está materialmente figurado na própria sentença ou quando ele é recuperado anaforicamente. Ao contrário, a convergência pode acontecer também quando o SN está aglutinado à instância verbal.

Vejamos:

(8a) Choveram cartas na redação

(8b) Cartas choveram na redação

(8c) Choveu cartas na redação

As ocorrências de (8a) a (8c) mostram a possibilidade de variação na concordância verbal e mobilidade na posição do SN sem alteração do fundamento referencial das sentenças. 
Além disso, trata-se de ocorrências nas quais o verbo apresentou-se como condensativo ${ }^{3}$, tendo em vista que os lugares de sujeito e objeto se ancoram em um mesmo campo de referência designado por "cartas". Portanto, estas ocorrências podem ser consideradas como sendo aquelas nas quais há convergência dos lugares sintáticos de sujeito e objeto direto no mesmo SN.

Por sua vez, observemos as seguintes orações:

(9) Choveu.

(10) Trovejou.

(11) Relampejou.

(12) Ventou.

Nestas sentenças, propomos que os SNs "chuva", "trovão", "relâmpago" e "vento" estejam aglutinados, respectivamente, nos verbos "chover", "trovejar", "relampejar" e "ventar". De acordo com Dias (2002), em "Choveu ontem", "o sujeito está aglutinado na própria instância do verbo" (DIAS, 2002, p. 55). Porém, para Perini (1992, p. 80), em uma sentença como esta, "não há sujeito porque se trata do esperado, ou seja, chuva".

Primeiramente, a proposta de Perini vai de encontro à nossa definição de sujeito. Este autor adota o suporte distributivo (DIAS, 2002) para a conceituação das categorias sintáticas, isto é, para ele, sujeito é o termo que estabelece concordância com o verbo. Como em "Choveu" não existe um termo que estabeleça concordância com o verbo, o autor afirma que a sentença não possui sujeito. Entretanto, de acordo com a perspectiva que adotamos (DIAS, 2002), o sujeito é o lugar sintático que aciona a flexão verbal. Portanto, havendo flexão, há sujeito na sentença.

Quanto à afirmação de Dias (2002) segundo a qual o sujeito está aglutinado ao verbo, faz-se necessária uma observação. Ao afirmar que o sujeito é que está aglutinado ao verbo, subentende-se que o SN integrado de sentenças como "Choveu ontem" teria um status sintático único: sujeito. Entretanto, conforme propomos acima, quando o SN está lexicalizado, sentenças como (8a) apresentam todas as características de ocorrências com convergência. Por isso, ao invés de dizer que o sujeito está integrado à instância verbal, preferimos dizer que o SN está integrado à instância verbal. Este SN, por sua vez, possui um status sintático duplo, quando desmembrado do verbo. Assim, em "Choveu ontem", a convergência dos lugares sintáticos de sujeito e objeto se daria neste SN "chuva", que está aglutinado ao verbo.

Nesse sentido, nem o lugar de sujeito, nem o lugar de objeto estariam aglutinados ao verbo. Com efeito, os conceitos de anterioridade de predicação (DIAS, 2007), em

\footnotetext{
${ }^{3}$ Este conceito será trabalhado na seção 4.2.1.
} 
relação ao sujeito, e projeção ${ }^{4}$ (DIAS, 2005), em relação ao objeto, demonstram que os lugares sintáticos são categorias que não estão acopladas ao verbo. Assim sendo, a convergência ocorreria não na instância verbal, mas no SN "chuva" que está, virtualmente, aglutinado à instância verbal. É nele, portanto, que a convergência acontece.

Observemos ainda alguns aspectos do comportamento destes verbos:

(9a) "os donos do poder chovem benesses a fim de obter adeptos" (HOUAISS, 2001).

(10a) "A platéia trovejou aplausos" (HOUAISS, 2001).

(11a) "Seu olhar relampejou uma chispa de ira" (HOUAISS, 2001).

(12a) "O novo emprego ventou-lhes novos amigos" (HOUAISS, 2001).

Nestes casos, o SN se desmembra do verbo, na dimensão orgânica, tendo em vista que o objeto é lexicalizado. Entretanto, na dimensão semântica, há um desmembramento parcial, porque, apesar de os verbos serem destituídos dos traços "chuva", "trovão", "relâmpago" e "vento", eles ainda guardam outros traços semânticos que antes eram concomitantes a estes eliminados. Assim, os verbos "chover", "trovejar", "relampejar" e "ventar" ainda permanecem na sentença, guardando, respectivamente, feixes semânticos relativos a "precipitação", "estrondo", "fulgor" e "ato de fazer chegar, trazer inesperadamente" (HOUAISS, 2001). Entretanto, há uma destituição de traços, porque o SN lexicalizado, no lugar sintático de objeto, não é um cognato, mas "benesses", "aplausos", "uma chispa de ira" e "novos amigos".

De outro modo, podemos observar casos em que há um desmembramento também parcial, mas, desta vez, menos intenso que aquele apresentado de (9a) a (12a). Vejamos:

(9b) Choveu uma chuva fina.

(10b) Trovejaram trovões assustadores.

(11b) Relampejaram relâmpagos intensos à noite.

(12b) Ventaram ventos fortes.

Nestes casos, há um desmembramento porque o SN cognato é lexicalizado e, portanto, desaglutinado do verbo. Entretanto, não se trata de um desmembramento total porque, sendo lexicalizado o nome cognato, não há uma reversão da expectativa. Neste caso, a "desaglutinação" se justifica, como já foi comentado, pela necessidade de se atribuir uma especificação ao SN.

Assim, os verbos de (9b) a (12b) não só mantêm, respectivamente, seus feixes semânticos relacionados a "precipitação", "estrondo", "fulgor" e "ato de fazer chegar,

\footnotetext{
${ }^{4}$ Os conceitos anterioridade de predicação e projeção serão trabalhados na seção 4.
} 
trazer inesperadamente", como também aos feixes semânticos relacionados a "chuva", "trovão", "relâmpago" e "vento". O que ocorre é que, materialmente, na linearidade da sentença, estes feixes semânticos foram explicitados lexicalmente, acompanhados de uma adjetivação. Houve, portanto, um desmembramento de ordem sintática, mas não houve um desmembramento de ordem semântica, porque os verbos não foram destituídos de traços semânticos.

Em consideração, portanto, à possibilidade de desmembrar o SN na linearidade da sentença e de destituir feixes semânticos do verbo, vejamos a seguinte escala:

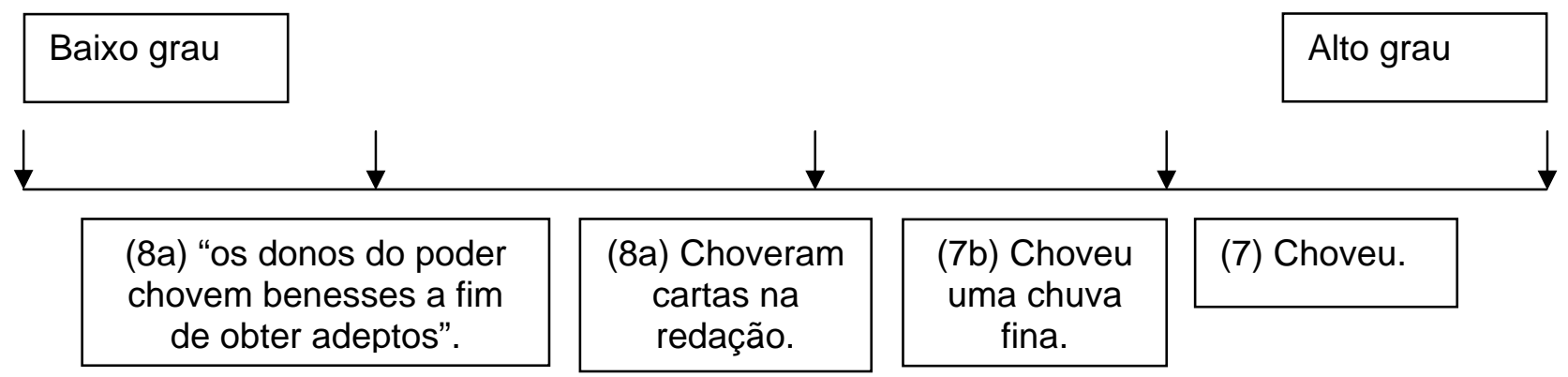

Nesta escala, observamos que cada uma dessas sentenças ocupa diferentes posições, de acordo com a intensidade do desmembramento estabelecido. Além disso, observamos que, mesmo havendo desmembramento, nenhuma destas sentenças ocupa o grau mais baixo na escala de concomitância, porque este desmembramento é parcial.

\section{A convergência de sujeito e objeto no SN aglutinado}

No início da seção 3, propomo-nos a fazer, em primeira instância, uma análise da integração do SN, na instância verbal. Posteriormente, ressaltaríamos a possibilidade de uma convergência dos lugares sintáticos de sujeito e objeto direto, neste SN aglutinado. Antes disso, porém, faz-se necessária uma explicitação de, pelo menos, duas formulações inseridas neste trabalho: o conceito de lugar sintático e a tipologia proposta acerca dos verbos que favorecem a convergência.

\subsection{O conceito de lugar sintático}

Dias (2002), em revisão às concepções de sujeito mais recorrentes na Lingüística, propõe a existência de três diferentes suportes que definem esta categoria: o distributivo, o atributivo e o operativo. O suporte distributivo é aquele que conceitua sujeito como o termo com o qual o verbo estabelece concordância. Por sua vez, o suporte atributivo é aquele que define esta categoria como sendo um lugar gerado pela grade argumental do verbo. Por último, o suporte operativo é aquele que busca as condições sob as quais este lugar será ocupado ou não. 
Interessa-nos, neste artigo, uma discussão mais focalizada no suporte atributivo. Assim, observamos que não deixa de existir um ponto de contato entre a noção de actante e o conceito de lugar sintático. Este ponto de contato se estabelece, tendo em vista que tais categorias não são compreendidas como itens lexicais (suporte distributivo), mas como espaços de ocupação (suporte atributivo). No entanto, uma das diferenças entre o conceito de actante e o de lugar sintático aparece na resposta para a seguinte questão: como são constituídos estes espaços? Na seção seguinte, propomo-nos a respondê-la. Por sua vez, na seção 4.2, apresentaremos os desdobramentos que uma abordagem enunciativa do conceito de lugar sintático pode ter, quais sejam, os conceitos de verbo condensativo e anterioridade.

\title{
4.1.1 O suporte atributivo: uma análise contrastiva dos conceitos de actante e lugar sintático
}

Para Vilela (1999),

\begin{abstract}
valência é a capacidade que um dado lexema (palavra) tem, por força de seu significado lexical, de abrir à sua volta um determinado número de lugares vazios e de prever a natureza e a forma dos termos que podem ou devem preencher esses lugares. Assim, o verbo dar prevê três lugares vazios (...) O Fernando deu um lindo cachecol à sobrinha (VILELA, 1999, p. 97, grifos do autor).
\end{abstract}

O verbo "dar", portanto, é o predicado, "portador básico da valência" (VILELA, 1999, p. 328). Ainda, acrescenta o autor: "Neste enquadramento, consideramos o sujeito tradicional como um complemento (...) também ele é previsto e selecionado pelo verbo." (VILELA, 1999, p. 331). Neste ponto, é importante ressaltar que os actantes (lugares vazios) estão "inscritos no significado do verbo" (VILELA, 1999, p. 331), isto é, são inerentes ao seu significado.

Diferentemente, na perspectiva que adotamos, nem sujeito, nem objeto se constituem por causa do significado do verbo. Adotamos, portanto, um modo diferente de operar com o suporte atributivo.

De acordo com Guimarães (1996),

Uma forma é na língua o que ela se tornou pela história de seus funcionamentos na enunciação. Deste modo, deve-se considerar que a língua tem em si a memória desta história, ou seja, a língua carrega na sua estrutura as marcas de seu passado. (GUIMARÃES, 1996, 27).

Sendo assim, objeto é um lugar sintático projetado pelo verbo (DIAS, 2005), mas esta projeção não está ancorada no significado dele. Para nós, qualquer que seja o significado apresentado pelo verbo, a projeção do objeto se dá, porque este lugar foi sedimentado no percurso histórico e enunciativo do verbo em questão. Assim, o objeto se 
constitui, dentre outros motivos, porque o verbo carrega uma memória de ocorrências com ocupação deste lugar sintático.

Quanto ao sujeito, trata-se também de um lugar sintático que não é projetado pelo verbo (DIAS, 2002). Este lugar é arregimentado pela enunciação e é responsável por acionar a flexão verbal. Por isso, o verbo está submetido à existência deste lugar sintático para que ele saia de seu "estado de dicionário" (DIAS, 2002, 53) e se incorpore em um enunciado. Este acionamento da flexão, por sua vez, demonstra que não há sentença sem sujeito. Nesse sentido, tendo em vista que a flexão é a manifestação da articulação entre este lugar e o verbo, ela avisa que, mesmo não sendo ocupado, ele está na sentença.

Portanto, os lugares sintáticos de sujeito e objeto direto não são categorias inerentes ao verbo, como são concebidos os actantes. Ao contrário, a própria constituição orgânica destes lugares é resultado da memória de enunciação que permeia suas ocorrências. Assim, conforme propusemos, uma das diferenças que distingue actantes e lugares sintáticos é o modo como se concebe a constituição destas categorias.

\subsection{Desdobramentos da análise enunciativa dos lugares sintáticos}

\subsection{1 "ter" e "haver": verbos condensativos}

Tendo em vista este percurso na direção de apresentar os pontos contrastantes entre actantes e lugares sintáticos, podemos alçar o seguinte ponto de nosso trabalho: verbos como "ter" e "haver", em "Houve problemas" ou em "Teve problemas", não podem ser considerados como monoargumentais, dentro da perspectiva adotada neste trabalho.

Conforme propomos, o lugar de sujeito é responsável por acionar a flexão verbal, e o lugar de objeto é projetado pelo verbo. Portanto, nestas sentenças, o verbo flexionado marca a existência do lugar de sujeito. Além disso, tais verbos guardam uma memória de ocupação do lugar do objeto, que, no caso, pode ser ocupado por "problemas". Logo, estes dois lugares sintáticos arregimentam a constituição orgânica dos verbos "ter" e "haver", nas orações referidas.

Entretanto, estes verbos têm um comportamento bastante distinto de verbos como "matar". Verbos como "haver" se caracterizam por uma condensação da ancoragem dos dois lugares sintáticos, em um único campo de referência. Diferentemente, a ancoragem dos lugares de sujeito e objeto, em sentenças com "matar", dá-se em campos de referência distintos. Por esta razão, utilizaremos a expressão "verbos que se apresentam como condensativos", para nos referirmos aos verbos que ocorrem em sentenças com convergência. 


\subsubsection{A anterioridade na compreensão do lugar de sujeito}

Dias (2007) reafirma que o lugar de sujeito é o responsável por retirar o verbo de seu estado virtual, acionando a flexão. Além disso, o autor explica que o acionamento do verbo pelo sujeito advém de um "ponto de partida" configurado enunciativamente: a anterioridade de predicação. Assim, Dias (2007) faz uma distinção entre anterioridade actorial e anterioridade predicativa. A anterioridade actorial é representada pela proposta segundo a qual o sujeito pode exercer papéis temáticos, dentre eles, o de agente. Por sua vez, a anterioridade de predicação é o fato de que o sujeito é "o "ponto de partida" na enunciação para arrebatar o verbo da sua condição de infinitivo" (DIAS, 2007). A seguir, veremos de modo mais detalhado esta diferença.

\subsubsection{A anterioridade actorial}

A compreensão de categorias, tais como animacidade e agentividade, liga-se a fatores de ordem ontológica. Trata-se, portanto, de algo secundário na análise, tendo em vista que, em nossa perspectiva, a referência é constituída em uma dimensão enunciativa.

Entretanto, para autores como Coelho et al. (2001, 21),

(i) verbos que selecionam argumentos necessariamente [+animados] privilegiam construções SV; (ii) verbos que selecionam argumentos [+/-animados] privilegiam construções VS, principalmente quando o argumento selecionado é [-animado].

Por exemplo, o verbo "trabalhar" (COELHO et al., 2001, 21) é prototípico de (i), ou seja, um verbo inergativo do qual se espera um argumento [+animado] e anteposto. No entanto, vejamos as seguintes ocorrências:

(13) "Meu marido trabalha no fundo de casa ele usa máquinas que faz muito barulho"

(14) "quanto mais rápido trabalha o operário, maior a quantidade de produtos que consegue produzir"6.

(15) "O presente artigo trabalha com os conceitos de organização, auto-organização e autopoiese, na perspectiva do conhecimento"7.

(16) “"É assim que age e trabalha a máquina do MITO e da fantasia?" Perguntou-se, enquanto sentia o seu peito oprimido"8.

\footnotetext{
${ }^{5}<$ http://br.answers.yahoo.com/question/index?qid=20070410084929AAEEJa5>Acesso em: 13 abr. 2007.

${ }^{6}<$ http://www.scielo.br/scielo.php?pid=S0103-65641999000200011\&script=sci arttext\&tlng=em $>$ Acesso em: 13 abr. 2007.

${ }^{7}<$ http://www.pgie.ufrgs.br/workshop4/programa.html> Acesso em: 13 abr. 2007.

${ }^{8}<$ http://www.jornalinfinito.com.br/series.asp?cod=62> Acesso em: 13 abr. 2007.
} 
Em (13), temos uma ocorrência tal qual esperada, o argumento é animado e está anteposto. A partir de (14), entretanto, nem tudo o que era previsto ocorre: embora o argumento "o operário" seja animado, ele não está anteposto. Em (15), por sua vez, o argumento "o presente artigo" já não é animado, algo que também não era esperado. Finalmente, em (15), "a máquina do mito e da fantasia" além de ser um argumento inanimado, está posposto, ocorrência pouco prevista pela proposição apresentada.

Com base nestes questionamentos, acreditamos que tais critérios nos levam a uma "corda bamba" na análise, porque, por vezes, o pesquisador terá de tomar decisões que podem ser arbitrárias ou baseadas em razões pouco claras e muito particulares. Por esses e outros motivos, optamos por não trabalhar com tais critérios neste projeto.

A seguir, delinearemos alguns pontos relevantes acerca do que estamos entendendo por anterioridade de predicação. Este conceito, diferentemente da anterioridade actorial, não se vale de noções ontológicas para a definição de sujeito.

\subsubsection{A anterioridade de predicação}

Conforme vimos, o lugar de sujeito não é projetado pela instância verbal, mas pela anterioridade de predicação, ou seja, o sujeito retira o verbo de seu estado de dicionário a partir de um "ponto de partida" (DIAS, 2007). Este "ponto de partida" da predicação está imbuído de duas dimensões. Uma delas está relacionada ao suporte atributivo, pois a anterioridade faz com que o lugar de sujeito acione a flexão. Por sua vez, uma outra dimensão da anterioridade está relacionada ao suporte operativo, pois o acionamento da flexão é motivado, não apenas por forças orgânicas, mas também por forças enunciativas.

Por isso, na dimensão operativa, a anterioridade estará vinculada a diferentes condições capazes de definir os tipos de realização do lugar de sujeito na sentença. Em alguns casos, por exemplo, a anterioridade pode estar submetida à necessidade de pontuar a referência deste lugar. Sendo assim, este lugar poderá ser ocupado por um SN, configurado como uma "base de definitude" (DIAS, 2002, 52), por exemplo, "Os vizinhos de Cláudio jogavam futebol aqui". Em outros casos, esta anterioridade vai se vincular a um "campo de orientação temática" (DIAS, 2002, 57). Nesse tipo, a referência do lugar de sujeito se ancora na "textualidade" (DIAS, 2002, 57), por exemplo, "Eles jogavam futebol aqui". Ainda, em outras ocorrências, a anterioridade vai ser determinada pelo "perfil que se sobressai da textualização de uma "verdade"' (DIAS, 2002, 60). Nestes casos, a anterioridade é arregimentada por uma configuração enunciativa de caráter universal. Por exemplo, em "Bebeu, jogou, furtou, beberá, jogará, furtará", todo aquele que "se adequar 
a este perfil estará se ajustando a uma verdade condensada nos próprios domínios do corpo textual no qual se insere a sentença" (DIAS, 2002, 60).

Tais tipificações do lugar de sujeito não serão detalhadas aqui. No entanto, a partir delas, importa ressaltar que o lugar de sujeito é projetado pela anterioridade de predicação. Esta anterioridade, por sua vez, possui uma dimensão orgânica, pois "concerne à instalação da perspectiva verbal" (DIAS, 2007), e uma dimensão enunciativa, pois é compreendida a partir das condições de ocupação do lugar de sujeito. Assim, o lugar de sujeito não é algo da instância verbal, mas algo da configuração enunciativa da sentença. Nesse sentido, o sujeito não é um complemento verbal.

\subsection{Verbos analisados sob o escopo da convergência}

Em observação aos critérios que fundamentam a noção de convergência, pode-se delimitar um contínuo de verbos, no português. Em uma extremidade deste contínuo, há verbos que parecem favorecer somente ocorrências com convergência. No intermédio, há verbos que podem ocorrer tanto em ocorrências com quanto sem convergência. Por sua vez, na outra extremidade do contínuo, há verbos não favorecem ocorrências com convergência.

\subsubsection{Grupo A: Verbos que parecem favorecer somente ocorrências com convergência}

Vejamos a tabela 1:

\begin{tabular}{|c|c|}
\hline CRITÉRIOS & Ocorreu uma reunião \\
\hline $\begin{array}{c}\text { Verbos que parecem se apresentar apenas } \\
\text { como condensativos }\end{array}$ & ?? A empresa ocorreu uma reunião \\
\hline Alteração na posição não afeta o FR & Uma reunião ocorreu/Ocorreu uma reunião \\
\hline Alteração na concordância não afeta o FR & Ocorreu reuniões/Ocorreram reuniões \\
\hline Campo de referência & Condensado \\
\hline
\end{tabular}

O verbo condensativo "ocorrer", por exemplo, parece atuar somente em sentenças com convergência. Por isso, uma sentença como "A empresa ocorreu uma reunião" não seria aceitável. Além disso, o FR de sentenças com "ocorrer" é insensível a alterações relacionadas à posição do $\mathrm{SN}$ e à concordância. Por fim, um último critério que caracteriza este verbo como pertencente ao grupo A é que a ancoragem dos lugares sintáticos de sujeito e objeto se deu, em um único campo de referência, designado por "uma reunião". 
4.3.2 Grupo B: Verbos que favorecem tanto ocorrências com quanto sem convergência

Vejamos agora a tabela 2:

\begin{tabular}{|c|c|c|}
\hline CRITÉRIOS & O menino chegou & $\begin{array}{c}\text { O menino chegou a mesa } \\
\text { para o canto }\end{array}$ \\
\hline $\begin{array}{c}\text { Apresentou-se como } \\
\text { condensativo? }\end{array}$ & Sim & Não \\
\hline $\begin{array}{c}\text { A alteração na posição afetou } \\
\text { o FR? }\end{array}$ & Não [Chegou o menino] & $\begin{array}{c}\text { Sim [A mesa chegou o } \\
\text { menino para o canto] }\end{array}$ \\
\hline $\begin{array}{c}\text { A alteração na concordância } \\
\text { afetou o FR? }\end{array}$ & $\begin{array}{c}\text { Não [Chegou os meninos/ } \\
\text { Chegaram os meninos] }\end{array}$ & $\begin{array}{c}\text { Não [Os meninos chegou (- } \\
\text { aram) a mesa para o canto] }\end{array}$ \\
\hline Campo de referência & Condensado & Distinto \\
\hline
\end{tabular}

Observa-se que, na sentença "O menino chegou", o verbo "chegar" apresenta o mesmo comportamento de "ocorrer", no grupo A. Portanto, esta é uma ocorrência com convergência. Diferentemente, "O menino chegou a mesa para o canto" é uma ocorrência sem convergência. Nesse caso, o verbo "chegar" não se apresenta como condensativo, os lugares sintáticos de sujeito e objeto direto são ancorados em domínios de referência distintos, e o FR é afetado pela alteração na ordem dos SNs. Por isso, verbos do grupo B favorecem tanto ocorrências com quanto ocorrências sem convergência.

\subsubsection{Grupo C: Verbos que parecem não favorecer ocorrências com convergência}

Por último, vejamos a tabela 3:

\begin{tabular}{|c|c|}
\hline CRITÉRIOS & EXEMPLOS \\
\hline Verbo não se apresenta como condensativo & Mataram cem pessoas neste semestre \\
\hline A alteração na posição do SN afeta o FR & Cem pessoas mataram neste semestre \\
\hline A alteração na concordância afeta o FR & Matou cem pessoas neste semestre \\
\hline $\begin{array}{l}\text { A ancoragem dos lugares sintáticos se dá em } \\
\text { campos de referência distintos }\end{array}$ & $\begin{array}{l}\text { Sujeito: espaço de indeterminação } \\
\text { Objeto: ancoragem em campo de referência } \\
\text { designado por "cem pessoas" }\end{array}$ \\
\hline
\end{tabular}

Verbos como "matar" não favorecem ocorrências com convergência, porque não se apresentam como condensativos. Sendo assim, a ancoragem dos lugares de sujeito e de objeto se dá em campos de referência distintos. Além disso, a alteração na posição do SN e na concordância verbal afeta o fundamento referencial de tais sentenças. Portanto, devido aos motivos apresentados, verbos como "matar" não favorecem ocorrências com convergência.

\subsection{A convergência no SN integrado a verbos como "chover"}

A abertura feita, neste artigo, para o conceito de lugar sintático e para a tipologia então proposta foi necessária para afirmarmos, finalmente, que verbos como "chover", 
"trovejar", "relampejar" e "ventar" fazem parte do grupo B, pois podem ocorrer em sentenças com ou sem convergência. Assim, de (9) a (12), a convergência se daria no SN que está integrado à instância verbal. Por sua vez, de (9b) a (12b), a convergência se daria nos SNs "chuvas finas", "trovões assustadores", "relâmpagos intensos" e "ventos fortes". Diferentemente, de (9a) a (12a), estes verbos não se apresentariam como condensativos. Por isso, estas não são ocorrências com convergência.

Sendo assim, as ocorrências de (8a) a (8c), de (9) a (12) e de (9b) a (12b) estariam alocadas no máximo grau de uma escala sintática de concomitância, conforme ilustra o esquema a seguir:

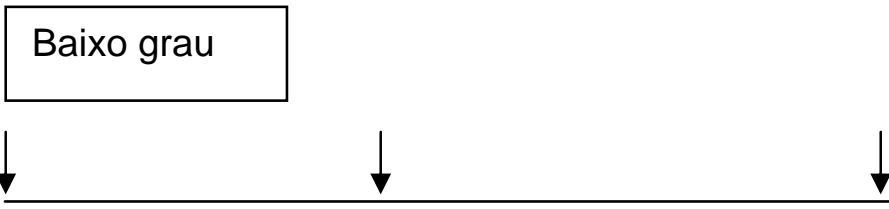

Alto grau

(8b) Cartas choveram na redação

(9) Choveu

(9b) Choveu uma chuva fina.

Nesta escala, propomos que tais sentenças ocupam o máximo grau, porque não há possibilidade de as duas categorias sintáticas, que constituem o SN, desmembrarem-se. Entretanto, um modo hipotético de desmembramento seria considerar que, em "Cartas choveram na redação", "cartas" seria sujeito. Por sua vez, em "Choveu cartas na redação", "cartas" seria objeto. Porém, quando o SN está no singular "Choveu uma chuva fina", a flexão verbal na terceira pessoa do singular neutraliza a diferença entre a forma tradicionalmente considerada "impessoal" 9 e a forma que estabelece concordância com o SN. Por isso, este desmembramento não é possível.

\section{A concomitância nos estudos de Lingüística Histórica}

Até então, mostramos como a concomitância pode ser analisada levando-se em conta fenômenos morfológicos e sintáticos. Ao explorarmos tais fenômenos de modo contrastivo, temos o intuito de direcionar uma explicação para aquilo que entendemos por convergência de sujeito e objeto direto. Com este mesmo intuito, apresentaremos, a seguir, um outro estudo que reconhece a concomitância de categorias lingüísticas, desta

\footnotetext{
${ }^{9}$ De acordo com o conceito adotado neste trabalho, se o verbo está flexionado, há sujeito na sentença. Por isso, “Choveu ontem” não seria oração sem sujeito.
} 
vez, do ponto de vista da Lingüística Histórica. Nesta abordagem, o termo "convergência" também é utilizado, entretanto, com um escopo diferente do nosso.

De acordo com Cardoso \& Cunha (1978), "Chamam-se FORMAS CONVERGENTES as palavras de étimo diverso que, diferentes na origem, acabam por confluir, no curso evolutivo de uma língua, para a mesma forma, para um vocábulo idêntico." (CARDOSO \& CUNHA, 1978, p. 158, grifos dos autores). Para estes autores, o tratamento das formas convergentes não pode ser visto

"como mera conseqüência (...) da evolução fonética (...) apesar de menos comuns
existem FORMAS CONVERGENTES que não se explicam pela simples evolução
dos fonemas. É o caso de novas aquisições léxicas, quer por empréstimo, quer
por formação interna, as quais podem confluir para formas homônimas já
existentes na língua" (CARDOSO \& CUNHA, 1978, p. 159, grifos dos autores).

Sendo assim, as formas convergentes resultantes de evolução fonética de formas latinas podem ser representadas por "rivu (subst.) e rideo (v.) > rio; tela (tecido) e taeda ("archote") > teia; nata (adj. e subst.) e natat (v.) > nada; dominu (senhor) e donu ("dádiva") > dom" (CARDOSO \& CUNHA, 1978, p. 159). Por sua vez, as formas convergentes resultantes de empréstimo podem ser:

"manga, "espécie de fruta", de origem malaia, converge para manga, "parte do vestuário", do latim manica; capão "mato ralo", de origem tupi, converge para capão, "referente aos galos", do latim cappone; lima, "fruta", de origem árabe, converge para lima, "ferramenta", do latim lima" (CARDOSO \& CUNHA, 1978, p. 159).

Por último, as formas convergentes resultantes de formação interna podem ser: "renda, deverbal de render, faz forma convergente com renda, "tecido", cuja origem é obscura." (CARDOSO \& CUNHA, 1978, p. 159).

Apesar da convergência de formas diversas em uma única forma do português, Cardoso \& Cunha (1978, p. 159) afirmam que este fenômeno, "em última análise, determina a variação semântica de uma mesma palavra ou a caracterização de palavras diversas, embora de idêntica forma.". A partir da leitura que fizemos destas afirmações, podemos propor que esta concomitância é de alto grau tendo em vista que, uma única forma lexical guarda, pelo menos, dois vocábulos diversos. Entretanto, esta concomitância não ocuparia o grau máximo na escala, tendo em vista que, ao guardar, em si, vocábulos diversos, a forma convergente possuirá variações semânticas, que serão recortadas pelo enunciado em que elas ocorrem. Por isso, mesmo sendo homônimas, estas palavras são constituídas pelas nuanças de sentidos determinadas pela memória dos vocábulos que a constituíram.

Sendo assim, em "Dom João VI foi rei de Portugal" e em "Santo Agostinho tinha o dom da profecia", a palavra "dom", embora seja a mesma graficamente, guarda a 
memória semântica dos étimos distintos que a constituem. Assim, ao inserir a forma convergente em diferentes enunciados, em cada um deles, um dos vocábulos formadores se sobressaiu em detrimento de outro. Por isso, houve um desmembramento, não total, porque esta palavra continua sendo homônima em qualquer um dos enunciados, mas parcial, porque, semanticamente, a memória de um dos vocábulos foi apagada. Vejamos, a seguir, um esquema que projeta tal raciocínio:
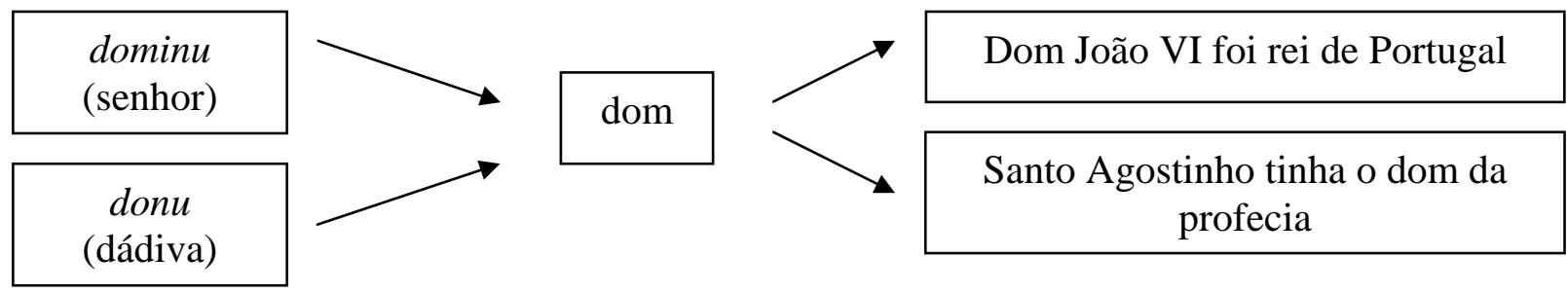

Diante disso, a noção de formas convergentes apresenta uma importante contribuição para nosso trabalho, tendo em vista a percepção de formas lingüísticas concomitantes. Entretanto, é preciso ficar claro que esta noção de convergência é diferente daquela com a qual trabalhamos.

\section{Considerações finais}

Ao compararmos ocorrências como "João martelou o prego", "André cuspiu" e "Choveu ontem", observamos que elas apresentam o mesmo grau de concomitância no que se refere à integração do SN. Na primeira, o SN "martelo" está integrado ao verbo "martelar"; na segunda, o SN "cuspe" está integrado ao verbo "cuspir"; e, na terceira, o SN "chuva" está integrado ao verbo "chover". Entretanto, elas se constituem de modo diferente. Em "João martelou o prego", o SN integrado é constitutivo de um adjunto adverbial. Por sua vez, em "André cuspiu”, o SN integrado é constitutivo do objeto. Por fim, em "Choveu ontem", o SN possui um status duplo, devido à convergência de sujeito e objeto.

Sendo assim, no que se refere à integração do SN no núcleo do predicado, estas sentenças apresentam o mesmo grau de concomitância, que é alto, mas não é máximo. No entanto, sentenças como "Choveu ontem" ocupam a máxima posição em uma escala sintática de concomitância, pois se trata de ocorrências com convergência dos lugares sintáticos de sujeito e objeto direto. Nesses casos, embora haja possibilidade de desmembramento do SN na linearidade da sentença, como em "Choveu uma chuva fina" ou em "Choveram cartas na redação", não há possibilidade de desmembrar as duas categorias sintáticas que convergem nos SNs "uma chuva fina" ou "cartas". Por isso, em uma escala sintática de concomitância, estas sentenças se localizam no grau máximo. 


\section{Referências bibliográficas}

CARDOSO, W. \& CUNHA, C. Estilística e gramática histórica: português através de textos. Rio de Janeiro: Tempo brasileiro, 1978. p. 151-159.

COELHO, I. L; WERNER, A.; ARDUIN, J. Uma contribuição para a descrição do português falado em Santa Catarina: a ordem verbo-sujeito. Working Papers em Lingüística, UFSC, n. 5, p. 7-24, 2001.

DIAS, L. F. \& PEREIRA, B.K. Da concomitância à convergência sintática: bases para uma análise da relação entre semântica e sintaxe. Faculdade de Letras, Belo Horizonte, 2007. Inédito.

DIAS, L. F. Fundamentos do sujeito gramatical: uma perspectiva da enunciação. In: ZANDWAIS, A. (Org). Ensaios: relações entre pragmática e enunciação. Porto Alegre: Sagra Luzzatto, 2002. p. 47-63.

. Problemas e desafios na constituição do campo de estudos da transitividade verbal. In: SARAIVA, M. E. F.; MARINHO, J. H. S. R.C. (Orgs.). Estudos da língua em uso: relações inter e intra-sentenciais. Belo Horizonte: PosLin, 2005. p. 101-122.

. Sintaxe e enunciação: o lugar do sujeito. Belo Horizonte: Faculdade de Letras da UFMG, 2007. Inédito.

GUIMARÃES, E. Enunciação, língua e memória. Revista da ANPOLL, n.2, p. 27-33, 1996. HOUAISS, A. Dicionário eletrônico Houaiss da língua portuguesa. Rio de Janeiro: Objetiva, 2001. CD-ROM.

<http://br. answers.yahoo.com/question/index?qid=20070410084929AAEEJa5>Acesso em: 13 abr. 2007.

<http://www.jornalinfinito.com.br/series.asp?cod=62> Acesso em: 13 abr. 2007.

<http://www.pgie.ufrgs.br/workshop4/programa.html> Acesso em: 13 abr. 2007. $<$ http://www.scielo.br/scielo.php?pid=S0103-

65641999000200011\&script=sci arttext\&tlng=em>Acesso em: 13 abr. 2007.

PERINI, M. A. \& FULGÊNCIO, L. Notas sobre a transitividade verbal. In: CLEMENTE, E. \& KIRST, M. H. B. Lingüística aplicada ao ensino de português. Porto Alegre: Mercado Aberto, 1992. p. 63-82.

SEILER, H. Le principe de concomitance. In: KRISTEVA, J.; MILNER, J.C.; RUWET, N. (orgs). Langue, discours, société. Paris: Éditions du Seuil, 1975. p. 166-207.

VILELA, M. Gramática da língua portuguesa: gramática da palavra, gramática da frase, gramática do discurso. 2.ed. Coimbra: Almedina, 1999. p. 97-98; 328-364. 